\title{
STUDI PERENCANAAN PENINGKATAN JALAN PADA RUAS JALAN JALUR LINTAS SELATAN GIRIWOYO - DUWET STA. 10+000 - STA. $15+000$
}

\author{
Agung Kurniawan ${ }^{* 1}$, Sigit Winarto ${ }^{2}$, Yosef Cahyo S.P ${ }^{3}$. \\ ${ }^{1,2,3}$ Fakultas Teknik, Universitas Kadiri. \\ e-mail:*1agungkurniaawan@gmail.com,2_sigit.winarto@unik-kediri.ac.id, \\ ${ }^{3}$ yosef.cs@unik-kediri.ac.id.
}

\begin{abstract}
The design improvement of the road, and cost estimate of the south path project, segment Giriwoyo-Duwet Sta.10+000 - Sta.15+00 aims to calculate the geometric, widening, thickness of the rigid pavement, thickness of the flexible pavement overlay, and cost estimates of the improvement road project. 2017 Traffic data and California Bearing Ratio data to calculate the thickness of the rigid pavement. The method used to design the geometric is "Tata Cara Perencanaan Geometrik Jalan Antar Kota Bina Marga 1997". The thickness of the rigid paving is calculated by means of a 20-year design plan; life uses "AASHTO 1993". The thickness of flexible pavement overlay with 20 years design life uses "Perencanaan Tebal Perkerasan Lentur Jalan Raya Dengan Metode Analisa Komponen Bina Marga 1987" and "Panduan Analisa Harga Satuan Bina Marga 1995" to calculate the cost estimation. From the calculation of the road known that thickness of rigid pavement for improvement is $15 \mathrm{~cm}$ with $10 \mathrm{~cm}$ lean mix concrete for subbase, and $5 \mathrm{~cm}$ with 2 meters roadside, flexible pavement for the surface. And the calculation of the flexible pavement overlay results is $6 \mathrm{~cm}$. From the calculation, the cost estimation of the improvement road is IDR. $5,015,899,000$
\end{abstract}

Keywords: Component Analysis Method, AASHTO, Widening, Rigid Pavement, Flexible Pavement Overlay, $R A B$

\begin{abstract}
Abstrak
Perencanaan Peningkatan Jalan Serta Rencana Anggaran Biaya Proyek Jalan Jalur Lintas Selatan Pada Ruas Giriwoyo - Duwet STA. 10+000 - STA. 15+00 bertujuan untuk menghitung pelebaran jalan, tebal perkerasan kaku jalan, tebal lapis tambahan (overlay) perkerasan lentur dan rencana anggaran biaya (RAB) proyek. Data lalu lintas tahun 2017 dan data California Bearing Ratio (CBR) untuk merencanakan tebal perkerasan kaku jalan. Metode yang digunakan untuk perhitungan tebal perkerasan kaku dengan umur rencana 20 tahun menggunakan panduan "AASHTO 1993". Untuk perhitungan lapis tambahan perkerasan lentur dengan umur rencana 20 tahun menggunakan panduan "Perencanaan Tebal Perkerasan Lentur Jalan Raya Dengan Metode Analisa Komponen Bina Marga 1987" dan untuk rencana anggaran biaya menggunakan "Panduan Analisa Harga Satuan Bina Marga 1995". Dari analisa perhitungan tebal perkerasan komposit untuk pelebaran jalan didapatkan tebal pelat beton $15 \mathrm{~cm}$, lapis pondasi bawah dengan campuran beton kurus (lean mix-concrete) setebal $10 \mathrm{~cm}$ dan lapis permukaan dari perkerasan lentur $5 \mathrm{~cm}$ dengan bahu jalan sepanjang 2 meter pada setiap sisi jalan. Untuk lapis tambahan (overlay) perkerasan lentur didapatkan penambahan setebal $6 \mathrm{~cm}$. Untuk perencanaan peningkatan jalan seperti terdapat pada uraian diperlukan biaya sebesar $\mathrm{Rp}$ 5.015.899.000,-
\end{abstract}

Kata Kunci : Metode Analisa Komponen, Metode AASHTO, Perkerasan Kaku, Perkerasan Lentur, RAB 


\section{PENDAHULUAN}

Proyek pembangunan jalan lintas selatan Giriwoyo -Duwet merupakan salah ruas jalan nasional yang berada di provinsi Jawa Tengah, Lebih tepatnya berada pada Kabupaten Wonogiri. Jalan ini menghubungkan DIY. Yogyakarta dengan Kabupaten Pacitan di Jawa Timur, [1][2][3].

Situs resmi Kabupaten Wonogiri, menuturkan bahwa Kabupaten Wonogiri merupakan daerah potensi pertanian tinggi, oleh karena itu peningkatan produksi pertanian, perlu didorong dan dikembangkan dengan peningkatan nilai tambah dari hasil hasil pertanian (industri pengolahan) dan industri kecil/kerajinan yang harus didukung dengan ketersediaan infrastruktur yang baik, [4][5]. Salah satu kecamatan yang merupakan daerah pertanian yang berperan dalam perkembangan ekonomi di Kabupaten Wonogiri adalah kecamatan Giriwoyo, [6][7][8]. Dengan dilaksanakan proyek pembangunan jalur lintas selatan Giriwoyo- Duwet diharapkan bisa mendorong perkembangan perekonomian dan perkembangan potensi alam di wilayah Giriwoyo. Proyek sepanjang $23.750 \mathrm{~km}$ ini melewati 4 kecamatan, diantaranya kecamatan Giriwoyo, Giritontro, Giribelah, Pracimantoro dan Kecamatan Duwet, [9][10][11].

Pada proyek ini dilakukan konstruksi peningkatan jalan lama dan pembangunan jalan baru. Dinas pekerjaan umum wilayah Semarang sebagai owner Proyek Pembangunan Jalur Lintas Selatan Giriwoyo-Duwet memperkirakan pusat keramaian pada jalur Lintas Selatan ini akan terjadi di Sta. 10+000 - Sta. 15+000, [12]. Dikarenakan Pada Sta.10+000 - Sta. 15.000 terdapat Pasar Giribelah yang menjadi pusat perekonomian masyarakat setempat, juga terdapat simpang jalan yang merupakan jalur alternatif menuju Kabupaten Pacitan Jawa Timur, [12][13]. Tetapi kondisi jalan yang ada dirasa tidak mampu menampung kapasitas kendaraan yang akan melalui jalur ini.

Sehingga perlu adanya peningkatan jalan di Ruas Jalan Giriwoyo-Duwet pada Sta. 10+000 - Sta. 15+000 untuk memperlancar lalu lintas perekonomian dan juga mengoptimalkan potensi yang dimiliki wilayah tersebut, [14][15][16]. Melihat Kondisi alam yang sebagian besar berupa pegunungan berbatu gamping, terutama di bagian selatan, sehingga juga perlu dilakukan perencanaan geometri jalan di Ruas Jalan Giriwoyo-Duwet pada Sta. 10+000 - Sta. 15+000 untuk menambah kenyamanan pengguna jalan dan juga menghindari terjadinya kecelakaan di wilayah tersebut [17][18].

\section{METODE PENELITIAN}

\subsection{Lokasi Penelitian.}

Penelitian ini dilakukan di proyek peningkatan jalan pada ruas jalan Lintas Selatan Giriwoyo-Duwet STA. 10+000 - STA. 15+000. 


\subsection{Kepustakaan}

Dalam PP No. 34 Tahun 2006 dijelaskan, jalan adalah prasarana transportasi darat yang meliputi segala bagian jalan, termasuk bangunan pelengkap dan perlengkapannya yang diperuntukkan bagi lalu lintas, yang berada pada permukaan tanah, di atas permukaan tanah, di bawah permukaan tanah dan/atau air, serta di atas permukaan air, kecuali jalan kereta api, jalan lori, dan jalan kabel.

Menurut Suryadharma pada jurnalnya, perkerasan kaku (rigid pavement) adalah perkerasan tegar/kaku/rigid dengan bahan perkerasan yang terdiri atas bahan ikat (semen portland, tanah liat) dengan batuan, [19]. Bahan ikat semen portland digunakan untuk lapis permukaan yang terdiri atas campuran batu dan semen (beton) yang disebut slab beton, [20]. Karena beton akan segera mengeras setelah dicor, dan pembuatan beton tidak dapat menerus, maka pada perkerasan ini terdapat sambungan-sambungan beton atau joint, [21]. Pada perkerasan ini juga slab beton akan ikut memikul beban roda, sehingga kualitas beton sangat menentukan kualitas pada rigid pavement [22].

\subsection{Alur Penelitian}

Pada studi perencanaan ini yang pertama dilakukan mencari informasi pada pemilik proyek terkait dengan data yang dibutuhkan, lalu mengumpulkan data proyek tersebut dimana data yang didapat berupa data primer dan sekunder yaitu : Data Teknis Jalan, Data Eksisting Jalan, Data CBR, Data Lalu lintas, Data Curah Hujan. Selanjutnya Mengumpulkan dan mempelajari segala bentuk kegiatan yang dapat mendukung dalam penyusunan laporan.

Pada studi perencanaan ini data yang dimiliki adalah data nilai CBR lapangan dikarenakan tanah dasar dilapangan telah mengalami urugan desebabkan tanah dasar dilokasi tersebut kurang bagus untuk dilakukan pekerjaan perkerasan lentur. Dengan tersedianya nilai CBR tersebut digunakan untuk menentukan daya dukung tanah dasar.

Data lalu lintas yang berupa LHR dianalisa untuk mendapatkan tingkat pertumbuhan kendaraan baik pertumbuhan rata-rata maupun pertumbuhan tiap jenis kendaraan sampai dengan akhir umur rencana. Untuk perkerasan jalan juga diperlukan data-data beban kendaraan, yaitu: beban yang berkaitan dengan beban sumbu kendaraan, volume lalu lintas, pertumbuhan lalu lintas dan konfigurasi roda.

Data yang telah didapatkan untuk pengolahan ini bertujuan untuk menentukan tebal perkerasan yang digunakan dalam perencanaan tersebut. Dalam hal ini untuk menghitung perencanaan perkerasan menggunakan Metode Analisa Komponen (MAK).

\section{HASIL DAN PEMBAHASAN}




\subsection{Penentuan Realiability $(R)$ dan $(Z R)$}

Mengacu pada AASHTO, 1993 didapat batasan nilai Realiability (R) yaitu 80 - 95.

Untuk selanjutnya ditetapkan nilai $\mathrm{R}=85 \%$. Dengan nilai $\mathrm{R}=85 \%$, didapatkan besar $Z_{R}$ yaitu sebesar -1,037. Standar deviasi untuk rigid pavement $:$ So $=0,30-0,40$, [23].

\subsection{Serviceability}

Terminal Serviceability index (pt) mengacu pada AASHTO, Initial Serviceability untuk rigid pavement : $(\mathrm{po})=4,5$

Penetapan parameter Serviceability menurut AASHTO, 1993, [23]:
a) Initial Serviceability : 4,5
b) Terminal Serviceability index jalur utama (major highways) $\quad: 2,5$
c) Terminal Serviceability index jalan lalu lintas rendah $\quad: 2,0$
d) Total Loss of Serviceability $\triangle \mathrm{PSI}=\mathrm{po}-\mathrm{p} t$

\subsection{Menentukan Modulus Reaksi Tanah Dasar}

Modulus reaksi tanah dasar (k) dapat dihitung menggunakan formula dan grafik penentuan modulus reaksi tanah dasar berdasar ketentuan CBR tanah dasar.

Pendekatan nilai Modulus reaksi tanah dasar (k) dapat menggunakan hubungan nilai CBR dengan $\mathrm{K}$

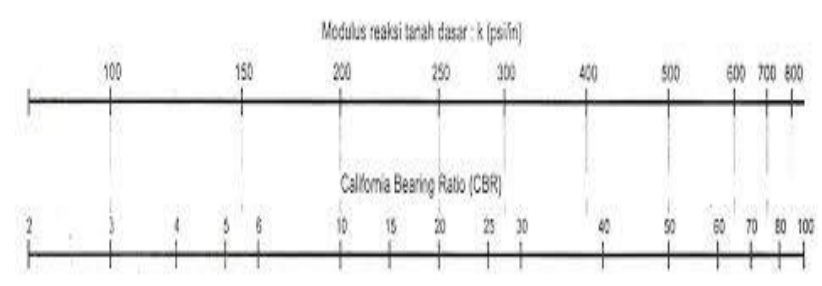

sumber: Portland Cement Assocoation

\subsection{Menentukan Modulus Elastisitas Beton}

Pada perencanaan ini digunakan kuat beton sesuai Spesifikasi Umum Volume II, jalan tol Cikampek-Padalarang (Tahun 2001) sebesar $375 \mathrm{~kg} / \mathrm{cm}^{2}$.

$$
\begin{array}{ll}
1 \mathrm{~kg} / \mathrm{cm}^{2} & =14,22 \mathrm{psi} \\
\mathrm{fc} & =375 \mathrm{~kg} / \mathrm{cm}^{2}=5,333 \mathrm{psi} \\
\mathrm{Ec} & =57000 \sqrt{5,333} \\
\mathrm{Ec} & =4162366 \mathrm{psi}
\end{array}
$$

Dibulatkan Ec $\quad=4200000 \mathrm{psi}$

$$
=292712 \mathrm{~kg} / \mathrm{cm}^{2} \text { dibulatkan } 300000 \mathrm{~kg} / \mathrm{cm}^{2}
$$




\subsection{Menentukan Flexural Strength}

Kekuatan beton harus dinyatakan dalam nilai kuat tarik lentur (flexural strength) umur 28 hari, yang didapat dari hasil pengujian balok (ASTM C-78) yang besarnya secara tipikal sekitar 3-5 MPa (30-50 kg/cm²). Pada umumnya Flexural Strength (modulus of rupture): $\mathrm{Sc}^{\prime}=45$ $\mathrm{kg} / \mathrm{cm}^{2}$.

$$
\mathrm{Sc}^{\prime}=45 \mathrm{~kg} / \mathrm{cm}^{2}=640 \mathrm{psi}=4,5 \mathrm{Mpa}
$$

\subsection{Menentukan Load Transfer}

Load Transfer Coefficient (J) mengacu pada AASHTO, 1993 [23] Didapatkan nilai J sebesar 2.5.

\subsection{Persamaan Penentuan Tebal Pelat (D)}

Untuk menghitung tebal perkerasan kaku digunakan persamaan :

$$
\begin{gathered}
\log _{10} W_{18}=Z_{R} \cdot S_{o}+7,35 \log _{10}(D+1)-0,06+\frac{\log _{10}\left[\frac{\Delta P S I}{4,5-1,5}\right]}{1+\frac{1,624 \times 10^{7}}{(D+1)^{8,46}}} \\
+\left(4,22-0,32 \cdot p_{t}\right) \times \log _{10} \frac{S_{c}^{\prime} \cdot C_{d} \times\left[D^{0,75}-1,132\right]}{215,63 \times J \times\left[D^{0,75}-\frac{18,42}{\left(E_{c}: k\right)^{0,25}}\right]}
\end{gathered}
$$

Untuk tebal perkerasan digunakan cara coba-coba sampai ruas kanan menghasilkan nilai yang lebih besar atau sama dengan ruas kiri.

Dicoba menggunakan tebal 5,81 inc $(14,757 \mathrm{~cm})$, dimasukkan pada persamaan sehingga dihasilkan,

$5,84=(-0,294)+6,123-0,06+(-0,046)+(-11,78) \times 0,00064)$

$5,84=5,84$

Dengan tebal perkerasan rencana yang dicoba, ruas sebelah kanan sama dengan ruas kiri sehingga tebal perkerasan bisa digunakan yaitu dengan tebal 5,81 inc $(14,757 \mathrm{~cm})$.

\subsection{Penentuan Dowel/ Ruji}

Untuk menentukan diameter, panjang dan jarak pemasangan dowel didapatkan diameter dowel adalah $3 / 4$ inc dengan panjang dowel adalah 18 inc dan dipasang dengan jarak antar dowel 12 inc. 


\subsection{Desain Perkerasan Komposit}

Perencanaan komposit yang digunakan adalah pendekatan desain overlay hotmix diatas rigid pavement yang mengacu pada AASHTO guide for design of pavement structures 1993.

Prosedur, parameter-parameter perencanaan mengikuti metode perencanaan rigid pavement diatas dengan gabungan overlay diatas rigid pavement tersebut, sebagai berikut :

$$
\begin{aligned}
& D_{\mathrm{ol}}=\mathrm{A}\left(\mathrm{D}_{\mathrm{f}}-\mathrm{D}_{\mathrm{eff}}\right) \\
& \mathrm{A}=2.2233+0.0099(\mathrm{Df}-\text { Deff })^{2}-0.1534 \text { (Df - Deff) } \\
& =2.2233+0.00255-0.07792 \\
& =2.15 \mathrm{inc} \\
& D_{\text {eff }} \quad=F_{\text {jc }} \times F_{\text {dur }} \times F_{\text {fat }} \times D \\
& =0.98 \times 0.96 \times 0.97 \times 5.81 \\
& =5.30
\end{aligned}
$$

Dari data perhitungan yang suda dilakukan sebelumnya didapatkan data:

Tebal Pelat Beton efektif (Deff) = =5,30 inc

Tebal pelat beton $\left(\mathrm{D}_{\mathrm{f}}\right) \quad=5.81 \mathrm{inc}$

Tebal total perkerasan rencana (Df) $\quad=5.81 \mathrm{inc}$

Dol $=2.15 \times(5.81-5.30)$

$$
=1.09 \mathrm{inc}=3 \mathrm{~cm}<5 \mathrm{~cm}
$$

Menurut buku pedoman "Perencanaan Tebal Pekerasan Lentur Jalan Raya Dengan Metode Analisa Komponen, 1993” tebal minimum perkerasan lentur sebagai lapis permukaan adalah 5 $\mathrm{cm}$. Jadi tebal perkerasan lentur yang digunakan untuk lapis permukaan adalah $5 \mathrm{~cm}$. Dari hasil perhitungan didapatkan susunan lapisan tebal perkerasan komposit seperti terdapat pada Gambar 1. berikut:

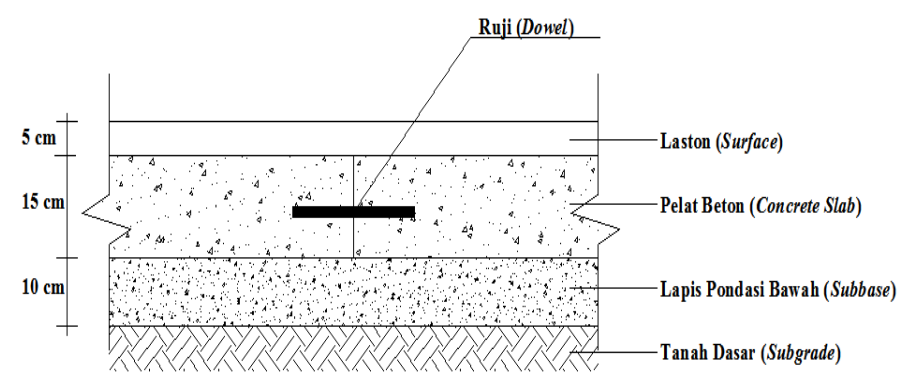

Sumber : Analisa Data

Gambar 1. Susunan Lapisan Tebal Perkerasan Komposit

\subsection{Desain Tebal Lapis Tambahan (Overlay)}

Tebal lapis tambahan jalan lama (1 jalur, 2 lajur), dari data perhitungan lalu lintas 2037 
seperti pada perhitungan sebelumnya, dinyatakan dalam umur rencana 20 tahun $\left(\mathrm{UR}_{20}\right)$, maka susunan lapis perkerasan lama adalah :
Lapis permukaan
$: 10 \mathrm{~cm}$
Lapis Pondasi Atas
$: 25 \mathrm{~cm}$
Lapisan Pondasi Bawah
$: 25 \mathrm{~cm}$

Untuk perhitungan pelapisan tambahan (overlay), diperlukan penilaian terhadap kondisi perkerasan jalan lama (SKBI 2.3.26,1987). Kondisi jalan lama sudah mengalami banyak retakan, nilai kondisi perkerasan jalan lama ditetapkan sebesar 40\% (Berdasarkan ketentuan Bina Marga, 1987). Selanjutnya perhitungan tebal lapis tambahan digunakan rumus :

$$
\begin{aligned}
& \text { ITP }_{\text {ada }}=\left(40 \% \cdot \mathrm{a}_{1} \cdot \mathrm{D}_{1}\right)+\left(100 \% \cdot \mathrm{a}_{2} \cdot \mathrm{D}_{2}\right)+\left(100 \% \cdot \mathrm{a}_{3} \cdot \mathrm{D}_{3}\right) \\
& =(40 \% \times 0,4 \times 10)+(100 \% \times 0,14 \times 25)+ \\
& \text { (100\%x0,12x25) } \\
& =8,1 \\
& \square \text { ITP }=\text { ITP }_{\text {perlu }}-\text { ITP }_{\text {ada }} \\
& =10,5-8,1 \\
& =2,4
\end{aligned}
$$

Dari perhitungan diatas, dihasilkan tebal lapis tambahan setebal $6 \mathrm{~cm}$. Sehingga susunan lapisan perkerasan jalan lama menjadi seperti terdapat pada Gambar 2.

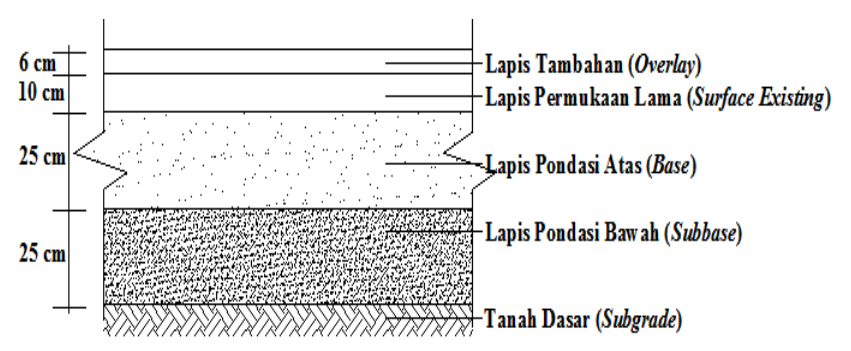

Sumber : Analisa Data

Gambar 2. Susunan Lapisan Tebal Perkerasan Komposit

\subsection{Rencana Anggaran Biaya}

Setelah menemukan hasil tebal perkerasan kaku dengan metode AASHTO. Selanjutnya dilakukan perhitungan volume pekerjaan untuk mengetahui berapa rencana anggaran biaya yang dibutuhkan untuk pelaksanaan pembangunan Jalan Jalur Lintas Selatan Ruas Giriwoyo - Duwet STA.10+000-STA 15+000 dengan tahapan perhitungan sebagai berikut : 
1. Perhitungan Volume Pekerjaan

Galian Pelebaran

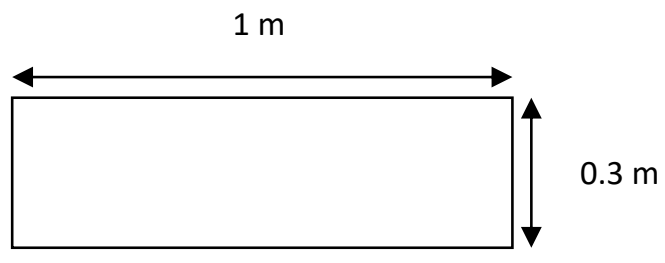

$$
\begin{aligned}
\text { Volume Galian Pelebaran per } \mathrm{m}^{3} & =\mathrm{p} \times 1 \times \mathrm{t} \\
& =1 \mathrm{~m} \times 1 \mathrm{~m} \times 0.3 \mathrm{~m} \\
& =0.3 \mathrm{~m}^{3}
\end{aligned}
$$

2. Pelat Beton K-250

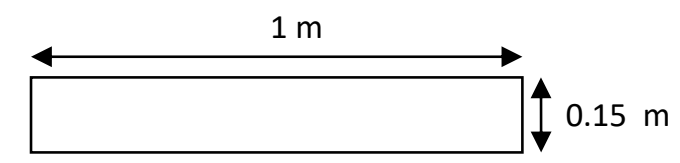

Volume Pelat Beton K-250 per $\mathrm{m}^{3} \quad=\mathrm{p} \times 1 \times \mathrm{t}$

$=1 \mathrm{mx} 1 \mathrm{~m} \times 0.15$

$=0.15 \mathrm{~m} 3$

3. Laston MS 744 (Overlay)

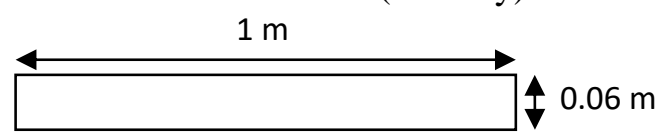

Volume Laston MS 744 (Overlay) per $\mathrm{m}^{3} \quad=\mathrm{p} \times 1 \times \mathrm{t}$

$$
\begin{aligned}
& =1 \mathrm{~m} \times 1 \mathrm{~m} \times 0,06 \mathrm{~m} \\
& =0,06 \mathrm{~m}^{3}
\end{aligned}
$$

1 ton aspal dapat digunakan untuk 2,32 $\mathrm{m}^{3}$. Maka kebutuhan Laston MS $744=\frac{0,06}{2,32}=0,026$ ton.

4. Laston MS 744 ( Jalan Baru)

$1 \mathrm{~m}$

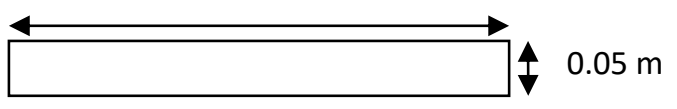

Volume Laston MS 744 ( Jalan Baru) per m³

$$
\begin{aligned}
& =\mathrm{p} \times 1 \times \mathrm{t} \\
& =1 \mathrm{~m} \times 1 \mathrm{~m} \times 0,05 \mathrm{~m} \\
& =0,05 \mathrm{~m}^{3}
\end{aligned}
$$


1 ton aspal dapat digunakan untuk 2,32 $\mathrm{m}^{3}$. Maka kebutuhan Laston MS $744=\frac{0,10}{2,32}=0,043$ ton

\subsection{Rekapitulasi Rencana Anggaran Biaya}

Dari hasil perhitungan harga satuan pekerjaan yang telah dilakukan didapatkan biaya total dari pembangunan Jalan Lintas Selatan Giriwoyo-Duwet sebagaimana berikut.

Tabel 1. Rekapitulasi Rancangan Anggran Biaya

\begin{tabular}{|c|c|c|c|c|c|c|c|}
\hline & & $\begin{array}{l}\text { REKA } \\
\text { rkiraan I }\end{array}$ & $\begin{array}{l}\text { PITULAS } \\
\text { arga Pekerj }\end{array}$ & & & & \\
\hline $\begin{array}{l}\text { Nama } \\
\text { Prop / }\end{array}$ & $\begin{array}{ll}\text { Paket } & \text { : Pembangunan Jalan Li } \\
\text { Kab / Kor : } & \text { Kabupaten Wonogiri }\end{array}$ & Selatan R & as Giriwoyc & $-\mathrm{D}$ & wet STA. $10+0$ & $0-S$ & ГA. $15+000$ \\
\hline No & Uraian & Satuan & Volume & & $\begin{array}{l}\text { Harga } \\
\text { Satuan } \\
\text { (Rupiah) }\end{array}$ & & $\begin{array}{l}\text { Jumlah } \\
\text { Harga } \\
\text { (Rupiah) }\end{array}$ \\
\hline 2. & $\begin{array}{l}\text { Umum } \\
\text { Mobilisasi } \\
\text { Pekerjaan Tanah }\end{array}$ & LS & 1 & & $178,267,872.9$ & & $178,267,872.92$ \\
\hline & Persiapan Badan Jalan & M2 & 35,000 & $\mathrm{Rp}$ & 635.75 & $\mathrm{Rp}$ & $22,251,135.46$ \\
\hline & Galian & M3 & 9,000 & $\mathrm{Rp}$ & $86,931.04$ & $\mathrm{Rp}$ & $782,379,382.55$ \\
\hline 3. & $\begin{array}{l}\text { Timbunan Bahu Jalan } \\
\text { Perkerasan Beton }\end{array}$ & M3 & 6,000 & $\mathrm{Rp}$ & $29,068.94$ & $\mathrm{Rp}$ & $174,413,612.93$ \\
\hline & Pelat Beton & M3 & 1,500 & $\mathrm{Rp}$ & $985,263.43$ & $\mathrm{Rp}$ & $1,477,895,146.64$ \\
\hline & Lapis Pondasi Bawah (LC) & M3 & 1,000 & $\mathrm{Rp}$ & $790,775.89$ & $\mathrm{Rp}$ & $790,775,888.39$ \\
\hline 4. & $\begin{array}{l}\text { Dowel } \\
\text { Perkerasan Aspal }\end{array}$ & KG & 4,450 & $\mathrm{Rp}$ & $14,705.32$ & $\mathrm{Rp}$ & $65,438,689.32$ \\
\hline & Lapis Resap Pengikat (Primecoat) & Liter & 21,000 & $\mathrm{Rp}$ & $13,597.34$ & $\mathrm{Rp}$ & $285,544,049.87$ \\
\hline & Laston MS 744 OVERLAY & Ton & 647 & $\mathrm{Rp}$ & $907,681.76$ & $\mathrm{Rp}$ & $586,863,204.33$ \\
\hline & Laston MS 744 JALAN BARU & Ton & 216 & $\mathrm{Rp}$ & $909,809.25$ & $\mathrm{Rp}$ & $196,079,580.37$ \\
\hline (A) Jur & nlah Harga Pekerjaan (termasuk Bia & mum dan & Keuntungan & & & $\mathbf{R p}$ & $4,559,908,562.78$ \\
\hline (B) $\mathrm{Pa}$ & ak Pertambahan Nilai $(\mathrm{PPN})=10 \%$ & & & & & $\mathbf{R p}$ & $455,990,856.28$ \\
\hline (C) JU & MLAH TOTAL HARGA PEKERJ & $=(\mathrm{A})+$ & & & & $\mathbf{R p}$ & $5,015,899,419.06$ \\
\hline (D) $\mathrm{JU}$ & MLAH TOTAL HARGA PEKERJ & (PEMB & JLATAN) & & & $\mathbf{R p}$ & $5,015,899,000.00$ \\
\hline
\end{tabular}

Sumber : Analisa Perhitungan Data

\section{Terbilang : Lima Milyar Lima Belas Juta Delapan Ratus Sembilan Pulu Sembilan Ribu Rupiah}

\section{KESIMPULAN}

Dari perencanaan dan perhitungan pada bab sebelumnya, maka dapat diambil kesimpulan sebagai berikut:

1. Perencanaan pelebaran dengan menganalisa kondisi jalan existing, jumlah lalu lintas pada awal umur rencana, jenis dan kelas jalan didapatkan kebutuhan pelebaran 1 (dua) meter, dengan bahu jalan 2 (dua) meter pada masing masing sisi jalan.

2. Perencanaan tebal perkerasan komposit untuk pelebaran menggunakan Metode AASHTO (Amrican Association of State Higway and Transportation Officials) tahun 1993 didapat 
susunan tebal perkerasan untuk lapis permukaan laston MS 744 dengan tebal $5 \mathrm{~cm}$, pelat beton dengan tebal $15 \mathrm{~cm}$, dan lapis pondasi bawah menggunakan lean mix concrete setebal $10 \mathrm{~cm}$. Perencanaan pelapisan tambahan (overlay) untuk jalan lama menggunakan Metode Analisa Komponen SKBI. 2.3.28. 1987 didapatkan tebal lapis tambahan $6 \mathrm{~cm}$.

3. Perhitungan biaya menggunakan Harga Satuan Pekerjaan Wilayah Kabupaten Wonogiri didapat rencana anggara biaya proyek jalan jalur lintas selatan ruas Giriwoyo - Duwet Sta. 10+000 - Sta. 15+000 sebesar Rp 5.015.899.419,- (Lima miliar lima belas juta delapan ratus Sembilan puluh Sembilan ribu empat ratus Sembilan belas rupiah).

\section{SARAN}

Berdasarkan hasil perencanaan ini ada beberapa saran sebagai berikut :

1. Dalam perhitungan perkerasan data yang digunakan harus lengkap agar memudahkan perhitungan perencanaan.

2. Untuk menghasilkan suatu perencanaan yang baik dan benar standar yang digunakan sebagai dasar perhitungan dan perencanaan harus paten sehingga perencanaan terarah dengan mengacu pada standar tersebut. Untuk mendapatkan suatu proyek konstruksi yang tepat waktu, mutu dan biaya sebaiknya pelaksanaan suatu proyek konstruksi harus mempunyai straegi pelaksanaan yang tepat dengan penjadwalan yang baik karena straegi pelaksanaan yang dilakukan akan mempengaruhi waktu pelaksanaan dan anggaran biaya.

\section{UCAPAN TERIMAKASIH}

Dalam penyusunan artikel ini, penulis ucapkan terimakasih kepada dosen pembimbing dan Universitas Kadiri. Penulis berharap agar artikel ini dapat bermanfaat bagi pembaca.

\section{DAFTAR PUSTAKA}

[1] E. N. Julianto, "Hubungan Antara Kecepatan, Volume Dan Kepadatan Lalu Lintas Ruas Jalan Siliwangi Semarang,” J. Tek. Sipil dan Perenc., vol. 12, no. 2, pp. 151-160, 2010.

[2] S. Awiyaningsih, H. Moetriono, and S. W. Mudjanarko, “ANALISIS DAMPAK LALU LINTAS PEMBANGUNAN MALL LAGOON AVENUE SUNGKONO TERHADAP KINERJA SIMPANG DI JALAN MAYJEND SUNGKONO - HR MUHAMMAD SURABAYA," Tek. Eng. Sains J., vol. 2, no. 2, pp. 131-134, 2018.

[3] A. I. Candra et al., "PENGECEKAN KELAYAKAN BANGUNAN GEDUNG SMA NEGERI 1 KOTA KEDIRI YANG DIGUNAKAN UNTUK AKTIFITAS," Ukarst $J$. Univ. Kadiri Ris. Tek. Sipil, vol. 2, no. 2, pp. 108-116, 2019.

[4] R. H. Lalenoh, T. K. Sendow, and F. Jansen, “Analisa Kapasitas Ruas Jalan Sam Ratulangi 
Dengan Metode Mkji 1997 Dan Pkji 2014,” J. Sipil Statik, vol. 3, no. 11, pp. 737-746, 2015.

[5] O. Z. Tamin, Perencanaan dan Pemodelan Transportasi, Edisi Kedua. 2000.

[6] A. D. Limantara, A. I. Candra, and S. W. Mudjanarko, "Manajemen Data Lalu Lintas Kendaraan Berbasis Sistem Internet Cerdas Ujicoba Implementasi Di Laboratorium Universitas Kadiri,” 2017.

[7] R. Tamimi, S. Wahyuni, and E. Hidayah, "Kajian Evaluasi Sistem Drainase Jalan Srikoyo Kecamatan Petrang Kabupaten Jember,” Rekayasa Sipil, vol. 10, no. 2, pp. 106-113, 2016.

[8] A. Kholiq, "Perencanaan Tebal Perkerasan Lentur Jalan Raya Antara Bina Marga Dan Aashto'93 (Studi Kasus: Jalan Lingkar Utara Panyingkiran-Baribis Ajalengka)," $J$ Ensitec, vol. 1, no. 01, pp. 43-51, 2014, doi: 10.31949/j-ensitec.v1i01.15.

[9] B. A. Harsono, S. Winarto, and Y. C. S, "PERENCANAAN PENINGKATAN JALAN PADA RUAS JALAN PACITAN-NGADIROJO,”Jurmateks, vol. 1, no. 2, pp. 291-302, 2018.

[10] A. A. Saputra, S. Winarto, and A. Ridwan, "PERENCANAAN STRUKTUR BAJA PADA KONSTRUKSI EMPAT LANTAI PADA HOTEL JAYA BAYA,” Jurmateks, vol. 1, no. 2, pp. 248-258, 2018.

[11] A. I. Candra and E. Siswanto, "Rekayasa Job Mix Beton Ringan Menggunakan Hydroton Dan Master Ease 5010," J. CIVILA, vol. 3, no. 2, p. 162, 2018, doi: 10.30736/cvl.v3i2.258.

[12] D. Metode and A. Komponen, "Perencanaan tebal perkerasan lentur dengan metode analisa komponen," pp. 1-25, 1989.

[13] [Kementerian PUPR]. Kementerian Pekerjaan Umum dan Perumahan Rakyat direktorat jendral bina marga, "PELEANGAN UMUM DENGAN PASCAKUALIFIKASI PEKERJAAN KONSTRUKSI (E. LELANG)," J. Chem. Inf. Model., vol. 53, no. 9, pp. 1689-1699, 2013, doi: 10.1017/CBO9781107415324.004.

[14] Direktorat Jenderal Bina Marga, "Highway Capacity Manual Project (HCM)," Man. Kapasitas Jalan Indones., vol. 1, no. I, p. 564, 1997, doi: 10.1021/acsami.7b07816.

[15] E. Kusnandar, "Manual Kapasitas Jalan Indonesia 1997," J. Jalan dan Jemb., vol. 26, no. 2, pp. 1-11, 2009.

[16] [Kementerian PUPR]. Kementerian Pekerjaan Umum dan Perumahan Rakyat, "Perencanaan Perkerasan Jalan Beton Semen," p. 52, 2003.

[17] E. Nurfadzilah, S. Winarto, and Y. C. SP, "ANALISA JALAN RING ROAD NGAWI STA $3+200$ - STA 6+200 KABUPATEN NGAWI PROPINSI JAWA TIMUR," Jurmateks, vol. 1, no. 1, pp. 33-43, 2018.

[18] A. Badrujaman, "Perencanaan Geometrik Jalan Dan Anggaran Biaya Ruas Jalan Cempaka 
- Wanaraja Kecamatan Garut Kota,” J. Konstr., vol. 14, no. 1, pp. 25-34, 2016.

[19] A. Miraj, Y. Pandu, and J. T. Sipil, "Perencanaan Tebal Perkerasan Kaku ( Rigid Pavement ) Pada Ruas Jalan Tol Karanganyar - Solo Naskah Terpublikasi 2016 Perencanaan Tebal Perkerasan Kaku ( Rigid Pavement ) Pada Ruas Jalan Tol Karanganyar - Solo,” Naskah Terpublikasi, 2016.

[20] SNI15-2049-2004, "SNI 15-2049-2004 Semen Portland," Badan Standar Nas. Indones., pp. 1-128, 2004.

[21] Badan Standardisasi Nasional, "SNI 15-7064-2004 Semen portland komposit," 2004.

[22] M. M. Amin, A. D. Limantara, and S. Winarto, "UJI LABORATORIUM PEMANFAATAN BIO ENZIM (BIOCONC) SEBAGAI PEREDUKSI SEMEN PADA BATA BETON MUTU A,”Jurmateks, vol. 1, no. 1, pp. 56-65, 2018.

[23] J. J. Bester, D. Kruger, and A. Hinks, "Construction and demolition waste in South Africa," Proceedings of the International Conference on Sustainable Waste Management and Recycling: Construction Demolition Waste. pp. 63-70, 2004. 